EXTENDED REPORT

\title{
Long term effectiveness of intravenous immunoglobulin in Churg-Strauss syndrome
}

\author{
M G Danieli, M Cappelli, G Malcangi, F Logullo, A Salvi, G Danieli
}

Ann Rheum Dis 2004;63:1649-1654. doi: 10.1136/ard.2003.015453

See end of article for authors' affiliations

.....................

Correspondence to:

Dr M G Danieli, Istituto

Clinica Medica Generale,

Ematologia ed

Immunologia Clinica, Polo

Didattico Scientifico, Via

Tronto 20, 60020, Torrette

di Ancona, Italy;

eleonora@univpm.it

Accepted

29 December 2003
Objective: To study the long term effectiveness of intravenous immunoglobulin and plasmapheresis associated with prednisone and cyclophosphamide in Churg-Strauss syndrome.

Subjects and methods: We studied 18 subjects with new onset Churg-Strauss syndrome. All received the "standard" treatment based on prednisone $(1 \mathrm{mg} / \mathrm{kg} /$ day for 1 month and then slowly tapered) and cyclophosphamide ( $2 \mathrm{mg} / \mathrm{kg} /$ day for 6 months in severe cases). In nine patients, synchronised cycles with plasmapheresis and intravenous immunoglobulin $(2 \mathrm{~g} / \mathrm{kg}$ ) were repeated monthly for 6 months and every other month for a further three cycles. Clinical (disease activity monitored by Birmingham vasculitis activity score (BVAS) and damage index (modified Rankin score)) and functional (C reactive protein, blood eosinophil count, and electromyogram-electoneurogram) parameters were collected during treatment and the 3 year follow up period.

Results: After 12 months, all patients in the treatment group and four $(44 \%)$ in the control group were in remission. At the end of the 3 year follow up period, we documented significant differences in BVAS $(p<0.01)$, global damage $(p<0.02)$, modified Rankin score $(p<0.04)$, and the daily maintenance prednisone dose $(p<0.002)$ between the two groups. We found a tendency towards lower frequency of relapse and incidence of osteoporosis in the treatment group.

Conclusion: Complete clinical and functional recovery with a long term stable remission and a low incidence of side effects can be achieved by intravenous immunoglobulin associated with plasmapheresis in patients with Churg-Strauss syndrome.
$\mathrm{C}$ hurg-Strauss syndrome (CSS) is a necrotising vasculitis of medium and small sized vessels. The disease, firstly described in 1951 by the pathologists Churg and Strauss, ${ }^{1}$ is characterised by bronchial asthma, eosinophilia, and clinical evidence of systemic vasculitis associated with circulating antibodies to antineutrophil cytoplasmic antigen (ANCA)..$^{3}$

Corticosteroids and cytotoxic drugs are the cornerstone of therapy, and permit control of disease activity in the great majority of cases. ${ }^{4-6}$ However, half of the patients relapse within 2 years of achieving remission and experience substantial drug dependent morbidity. ${ }^{7}$ Moreover, neuropathy is present in about $95 \%$ of patients with $\mathrm{CSS}^{7}$ Therapeutic approach to the CSS associated neuropathy is still unresolved and resolution of the disability remains a critical issue in this group of patients. ${ }^{8}$

Effectiveness of intravenous immunoglobulin (IVIg) alone or as add on therapy has been evaluated in several types of ANCA associated vasculitis, ${ }^{9-12}$ and in various immune mediated neuropathies, ${ }^{13}$ even though its mechanisms remain only partially understood. Only case reports have been published on its use in CSS. ${ }^{14-16}$ Different mechanisms of action have been proposed to explain the beneficial effects of IVIg. The more relevant seem to be linked to an acceleration of the catabolism of the IgG antibodies. ${ }^{17}$

Previous reports suggested that repeated plasmapheresis $(\mathrm{PP})$ is effective against progressive and severe immunomediated diseases. ${ }^{18}$ The rationale underlying this approach is that PP removes humoral pathogenic substances from the circulation, and subsequent infusion of an immunosuppressant or an immunomodulatory agent prevents the consequent immune system rebound.

The aim of the present study was to evaluate the benefit and the safety of IVIg synchronised with PP in nine patients with CSS. Data were compared with those obtained with the "standard" treatment based on corticosteroids and cyclophosphamide.

\section{METHODS}

\section{Patient selection}

Between 1995 and 1999, nine consecutive patients were prospectively enrolled to receive IVIg synchronised with PP (treatment group). Subjects comprised patients who fulfilled the 1990 American College of Rheumatology criteria $^{19}$ for and the 1992 Chapel Hill Consensus Conference definition ${ }^{20}$ of CSS. In all cases, the disease was newly diagnosed. Exclusion criteria included serious infections in the previous 6 months, known malignancy, and other concomitant severe or uncontrolled disease. All patients enrolled in this study provided informed consent to the treatment protocol approved by the institutional review board. Patients at risk of pregnancy were advised to use adequate contraception during the study period and for 6 months after the end of the treatment.

Nine patients with new onset disease and similar baseline characteristics (table 1), fulfilling the inclusion criteria of this study, receiving the "standard" treatment (as above) and prospectively followed in our centre, were selected from our institute database of 32 patients with CSS to form a control group. None of the patients in the groups received antileukotriene treatment for asthma.

Abbreviations: ANCA, antineutrophil cyłoplasmic antigen; BVAS, Birmingham Vasculitis Activity Score; CSS, Churg-Strauss syndrome; EMG, electomyograph; ENG, electroneurograph; FFS, five factor score; $\mathrm{IVlg}$, intravenous immunoglobulin; PP, plasmapheresis; SNVDI, Systemic Necrotising Vasculitis Damage Index 
Table 1 Baseline characteristics in 18 patients with CSS treated with a "standard" prednisone/cyclophosphamide treatment with (treatment group) or without (control group) intravenous immunoglobulin synchronised with plasmapheresis. Five and four patients in each group (numbers 1-5 and 10-13), whose FFS values were $\geqslant 1$, received oral cyclophosphamide for 6 months (see Methods for details)

\begin{tabular}{|c|c|c|c|c|c|c|}
\hline Sex/age & $\begin{array}{l}\text { Clinical features } \\
\text { at the onset of } \\
\text { involvement }\end{array}$ & $\begin{array}{l}\text { Kind of } \\
\text { PNS or } \\
\text { CNS }\end{array}$ & FFS & BVAS & $\begin{array}{l}\text { Modified } \\
\text { Rankin } \\
\text { score }\end{array}$ & $\begin{array}{l}\text { MPO- } \\
\text { ANCA }\end{array}$ \\
\hline \multicolumn{7}{|c|}{ Treatment group } \\
\hline $1 / F / 55$ & $\begin{array}{l}\text { Systemic symptoms, skin ulcers, sinusitis, } \\
\text { alveolar opacities, ILD, myocardial infarct }\end{array}$ & AP & 1 & 30 & 4 & + \\
\hline $2 / M / 69$ & $\begin{array}{l}\text { Systemic symptoms, skin vasculitis, sinusitis, } \\
\text { alveolar opacities, ILD, proteinuria, } \Pi \text { arthritis }\end{array}$ & AP & 1 & 28 & 4 & + \\
\hline $3 / M / 44$ & $\begin{array}{l}\text { Systemic symptoms, palpable purpura, nasal } \\
\text { polyposis, pleurisy, myocarditis }\end{array}$ & MM & 1 & 24 & 3 & + \\
\hline $4 / F / 53$ & $\begin{array}{l}\text { Skin ulcers, retinal haemorrhage, sinusitis, } \\
\text { alveolar opacities, proteinuria }\end{array}$ & AP & 1 & 29 & 2 & - \\
\hline $5 / F / 57$ & $\begin{array}{l}\text { Systemic symptoms, alveolar opacities, } \\
\text { pleurisy, pericarditis, myocarditis }\end{array}$ & AP & 1 & 26 & 3 & - \\
\hline $6 / F / 56$ & Sinusitis, alveolar opacities & AP & 0 & 15 & 3 & - \\
\hline 7/F/69 & Sinusitis, alveolar opacities, $\Pi$ arthritis & $\begin{array}{l}\text { MM, } \\
\text { diplopia }\end{array}$ & 0 & 16 & 3 & - \\
\hline $8 / F / 43$ & $\begin{array}{l}\text { Systemic symptoms, nasal polyposis, alveolar } \\
\text { opacities, arthritis }\end{array}$ & $M N$ & 0 & 15 & 2 & + \\
\hline $9 / F / 33$ & Skin ulcers, sinusitis, alveolar opacities & MM & 0 & 19 & 1 & - \\
\hline \multicolumn{7}{|c|}{ Control group } \\
\hline $10 / F / 47$ & $\begin{array}{l}\text { Systemic symptoms, sinusitis, myocardial } \\
\text { infarct, renal impairment }\end{array}$ & $\begin{array}{l}\text { MM, } \\
\text { stroke }\end{array}$ & 2 & 31 & 4 & - \\
\hline $11 / M / 61$ & $\begin{array}{l}\text { Skin ulcers, sinusitis, alveolar opacities, } \\
\text { proteinuria }\end{array}$ & MM & 1 & 23 & 4 & - \\
\hline $12 / M / 28$ & $\begin{array}{l}\text { Sinusitis, alveolar opacities, intestinal } \\
\text { vasculitis }\end{array}$ & $M N$ & 1 & 15 & 3 & + \\
\hline $13 / F / 66$ & $\begin{array}{l}\text { Systemic symptoms, sinusitis, pleurisy, } \\
\text { pericarditis, intestinal vasculitis }\end{array}$ & MM & 1 & 25 & 2 & - \\
\hline $14 / M / 29$ & Systemic symptoms, nasal polyposis & $\begin{array}{l}\text { MM, } \\
\text { diplopia }\end{array}$ & 0 & 13 & 2 & + \\
\hline $15 / F / 59$ & Sinusitis, alveolar opacities & MM & 0 & 15 & 3 & + \\
\hline $16 / F / 46$ & $\begin{array}{l}\text { Systemic symptoms, sinusitis, pleurisy, } \\
\text { pericarditis }\end{array}$ & MM & 0 & 20 & 3 & + \\
\hline $17 / M / 48$ & Sinusitis, alveolar opacities & AP & 0 & 15 & 1 & - \\
\hline $18 / \mathrm{F} / 25$ & $\begin{array}{l}\text { Systemic symptoms, skin ulcers, alveolar } \\
\text { opacities, pleurisy, pericarditis }\end{array}$ & 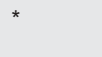 & 0 & 18 & 2 & + \\
\hline
\end{tabular}

\section{Clinical and functional assessment}

To assess the systemic syndrome fully, we adopted a standardised protocol for clinical and functional evaluation. At each assessment, all of the patients underwent a complete medical history and full physical examination. The neurological assessment comprised the patient's neurological history, a complete standard neurological examination, and electrodiagnostic studies. The functional state of the patients was clinically evaluated using the modified Rankin score. ${ }^{21}$ Peripheral neuropathy was classified clinically as true mononeuritis multiplex, overlapping mononeuritis multiplex, asymmetrical polyneuropathy, and symmetrical sensorimotor polyneuropathy. ${ }^{22}$

The biochemical analyses included a full blood count (eosinophilia was taken as $>10 \%$ eosinophils in the total white blood cell count), acute phase reactants ( $\mathrm{C}$ reactive protein (CRP); normal $<60 \mathrm{mg} / \mathrm{l}$ ), creatinine, liver function tests, urine analysis and sediment, and $24 \mathrm{~h}$ urinary protein. Investigation of antibodies directed against ANCA was performed by ELISA for PR3-ANCA and MPO-ANCA antibodies. ${ }^{23}$

Other tests included pulmonary function; the diffusion capacity of the lung for carbon monoxide expressed as a percentage of the predicted value (TLCO); chest radiography and high resolution computed tomography. Electromyograph-electroneurograph (EMG-ENG) measure- ments were obtained with a Viking Nicolet II and IV electromyograph according to the standard techniques. ${ }^{24}$ Other examinations were carried out where clinically indicated.

\section{Disease assessment}

The Birmingham Vasculitis Activity Score (BVAS) was selected to evaluate the activity of the disease at study entry and during the follow up period. ${ }^{25}$ At the onset, according to Guillevin et $a l^{26}$ the five factor score (FFS) defined the patients with a poorer outcome. At the last assessment, the Systemic Necrotising Vasculitis Damage Index (SNVDI) was employed to score the severity of vasculitis. ${ }^{27}$ In one subject in the control group, these vasculitis scores were recalculated because they were not initially performed.

\section{Treatment protocol}

At the onset, patients received the "standard" treatment based on prednisone and cyclophosphamide. Prednisone was started at $1 \mathrm{mg} / \mathrm{kg} /$ day for 1 month and then tapered to the maintenance dose of $10 \mathrm{mg} /$ day by month 6 . Five and four patients in each group whose FFS and/or BVAS values were $\geqslant 1$ and/or $\geqslant 20$, respectively, or presenting clinical and functional signs of severe disease, received oral cyclophos-phamide $(2 \mathrm{mg} / \mathrm{kg} /$ day in two divided doses, 
adapted to the neutrophil count, together with prednisone) for 6 months.

In nine patients, synchronised therapy (monthly synchronised cycles of PP followed by IVIg infusion) was added to this "standard" treatment. Patients received PP (Cobe Spectra and Baxter CS-3000) $50 \mathrm{ml} / \mathrm{kg}$, with $4 \%$ human albumin being the substitution fluid. The apheresis sessions were scheduled on days 1,3 , and 5 to avoid clotting disturbances. IVIg (Ig vena N IV ${ }^{\circledR}$; Sclavo, Siena, Italy) $1 \mathrm{~g} / \mathrm{kg}$ was infused at $5 \mathrm{~g} /$ hour on days 6 and 7 . In patients with renal or cardiac impairement, the rate of infusion was slower. This treatment was repeated monthly until month 6 and bimonthly for a further three cycles. Thereafter (month 18), patients who had improved received no therapy or a minimum predniso(lo)ne dosage to maintain remission (or to control asthma). Only one patient was treated with methotrexate ( $10 \mathrm{mg} /$ week) as a steroid sparing drug.

In the control group, according to the clinical and/or laboratory response to treatment, patients were given a low dose corticosteroid.

\section{Endpoints}

The primary endpoints were: $(a)$ the percentage of patients who achieved remission and $(b)$ the global severity of the syndrome at the end of the follow up period. Remission was defined as the resolution of the clinical manifestations of CSS (not considering asthma) and of the eosinophilia, lasting at least 6 months. Minor neurological sequelae of neuritis could persist. The patient was considered to be in treatment free, sustained remission when remission was maintained for at least 18 months after discontinuation of treatment. The global severity of the vasculitis was assessed by the SNVDI and the modified Rankin scores.

Predefined secondary endpoints were: $(a)$ the number of relapses, defined as new clinical manifestation(s) of CSS after a remission period lasting 6 months or worsening of previous features (not including asthma or eosinophilia); $(b)$ the mean corticosteroid dose necessary to maintain the remission; and (c) the incidence of treatment dependent side effects.

\section{Follow up}

In all patients, clinical status and laboratory parameters were evaluated and noted prior to the treatment, monthly until month 12 and bimonthly thereafter, or when clinically indicated. EMG-ENG was performed at the baseline and then repeated at months 8 and 12 and subsequently at least once a year. The type and severity of any adverse events were recorded. Osteoporosis was defined as a bone mineral density of more than 2.5 SD from the young adult peak mean.

\section{Statistical analyses}

Data collected in the clinical charts of the 18 patients were analysed using the NCSS statistical program. ${ }^{28}$ Quantitative variables were expressed as median and nonparametric 95\% confidence interval (CI). Owing to the small size of the samples, Mann-Whitney $U$ test was used for intergroup comparisons. Comparison between frequencies was performed by Fisher's exact test. Statistical significance was defined as $\mathrm{p}<0.05$.

\section{RESULTS}

\section{Characteristics of the patients}

Table 1 shows the baseline characteristics and presenting features of the 18 patients with CSS. There were no significant differences between the two groups with the respect of the various demographic, clinical and serological features. All of the patients suffered from asthma, requiring continuous therapy.

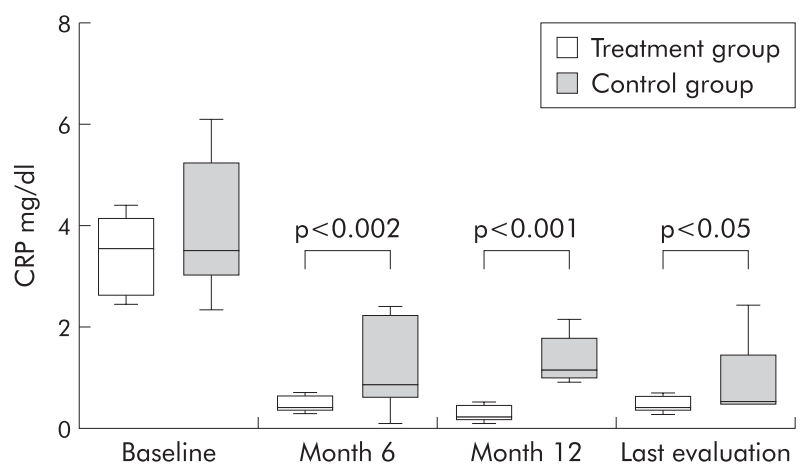

Figure 1 Box plots show the median values (solid line) plus 95\% confidence intervals of serum $C$ reactive protein (CRP, $\mathrm{mg} / \mathrm{dl}$ ) for treatment (white bars) and control (shaded bars) groups. At months 6 and 12 and at last assessment, patients receiving IVIg had a statistically significant difference in the CRP serum levels from those treated with a "standard" prednisone/cyclophosphamide treatment (Mann-Whitney $U$ test). Error bars represent the range.

Multisystemic involvement at the onset of the vasculitis process is detailed in table 1 . In particular, when referred to us, five and three patients in the treatment group had involvement of the peripheral nerve manifested respectively as asymmetrical polyneuropathy and mononeuritis multiplex. One patient in this group had isolated right peroneal mononeuritis. The neurological pattern was similar in the control group. There was no difference in the baseline modified Rankin scores between the two groups (median 3; CI 2 to 4 in both groups).

Pretreatment median FFS and BVAS values were not different between the two groups. All patients had elevated CRP values (fig 1), with no intergroup differences. Positivity to MPO-ANCA was detected in four and five patients in the treatment and control group, respectively.

\section{Clinical course and response to treatment during the first 18 months}

From the start of the IVIg infusions, we documented a clinical and functional improvement that was complete or worthwhile at month 6 (fig 2). At month 12, all of the patients in the treatment group in comparison to four $(44 \%)$ in the control group were in remission.

As for the neurological involvement, the modified Rankin score improved in all of the patients, except in two cases in

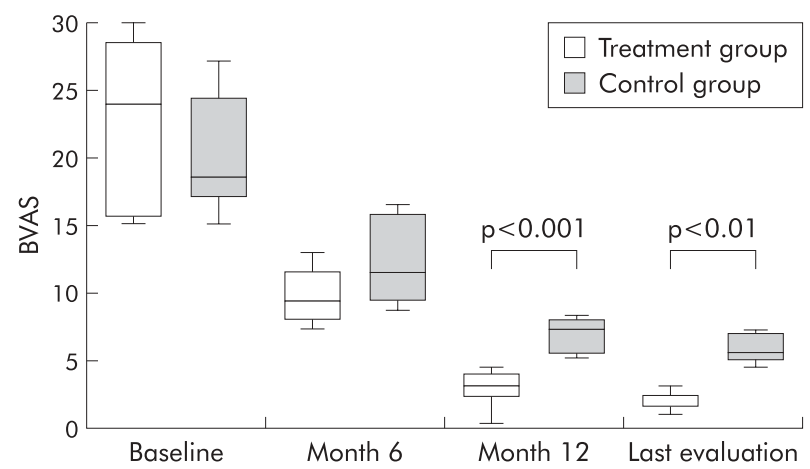

Figure 2 Box plots show the median values (solid line) plus 95\% confidence intervals of Birmingham Vasculitis Activity Score (BVAS) for treatment (white bars) and control (shaded bars) groups. At month 12 and at last assessment, patients receiving combined treatment had a statistically significant difference in the vasculitis activity scores than those treated with a "standard" prednisone/cyclophosphamide treatment (Mann-Whitney $U$ test). Error bars represent the range. 
Table 2 Outcomes in 18 patients with CSS treated with a "standard" prednisone/ cyclophosphamide treatment with (treatment group) or without (control group) intravenous immunoglobulin synchronised with plasmapheresis. The table shows the values at last assessment for SNVDI, BVAS and modified Rankin scores

\begin{tabular}{|c|c|c|c|c|c|c|c|}
\hline $\begin{array}{l}\text { No/Sex/ } \\
\text { age (years) }\end{array}$ & $\begin{array}{l}\text { Follow up } \\
\text { (months) }\end{array}$ & Relapse & Outcome & $\begin{array}{l}\text { Maintaining } \\
\text { drug (mg/day) }\end{array}$ & SNVDI & BVAS & $\begin{array}{l}\text { Modified } \\
\text { Rankin } \\
\text { score }\end{array}$ \\
\hline \multicolumn{8}{|c|}{ Treatment group } \\
\hline $1 / F / 55$ & 71 & No & SR & No & 5 & 2 & 2 \\
\hline $2 / M / 69$ & 37 & No & $\mathrm{R}$ & MTX & 3 & 2 & 2 \\
\hline $3 / M / 44$ & 68 & No & SR & No & 4 & 4 & 1 \\
\hline $4 / F / 53$ & 68 & Yes & SR & No & 4 & 2 & 1 \\
\hline $5 / F / 57$ & 52 & No & $\mathrm{R}$ & DFZ (6) & 5 & 4 & 1 \\
\hline $6 / F / 56$ & 44 & No & $\mathrm{R}$ & DFZ (6) & 3 & 2 & 1 \\
\hline $7 / F / 69$ & 36 & No & $\mathrm{R}$ & Methyl-PDN (4) & 5 & 2 & 1 \\
\hline $8 / F / 43$ & 33 & No & $\mathrm{R}$ & DFZ (6) & 3 & 2 & 0 \\
\hline $9 / F / 33$ & 32 & No & $\mathrm{R}$ & Methyl-PDN (4) & 2 & 1 & 1 \\
\hline \multicolumn{8}{|c|}{ Control group } \\
\hline $10 / F / 47$ & 108 & No & SR & No & 6 & 4 & 3 \\
\hline $11 / M / 61$ & 43 & Yes & $\mathrm{R}$ & Methyl-PDN (16) & 11 & 6 & 2 \\
\hline $12 / M / 28$ & 72 & Yes & $\mathrm{R}$ & DFZ (9) & 4 & 2 & 1 \\
\hline $13 / F / 66$ & 32 & No & $\mathrm{R}$ & PRD (10) & 5 & 4 & 2 \\
\hline $14 / M / 29$ & 36 & No & $\mathrm{R}$ & Methyl-PDN (8) & 5 & 3 & 1 \\
\hline $15 / F / 59$ & 42 & No & $\mathrm{R}$ & PRD (7.5) & 6 & 6 & 2 \\
\hline $16 / F / 46$ & 60 & No & $\mathrm{R}$ & PRD (7.5) & 5 & 6 & 2 \\
\hline $17 / M / 48$ & 66 & Yes & SR & No & 4 & 6 & 2 \\
\hline $18 / F / 25$ & 55 & Yes & $\mathrm{R}$ & Methyl-PDN (8) & 4 & 2 & 1 \\
\hline
\end{tabular}

the control group, in whom it was stable. EMG-ENG studies, performed at months 8 and 12, documented a sustained improvement in the upper and lower limbs of all patients, except two in the control group.

The elevated pretreatment median BVAS continued to decrease until month 12 , being, at that time, 4 (95\% CI 4 to 6) and 7 (95\% CI 7 to 10) for the treatment and control groups, respectively $(\mathrm{p}<0.001$, Mann-Whitney $U$ test). Fig 1 shows a statistically significant difference between the two groups in the serum levels of CRP during treatment and at the last follow up assessment. MPO-ANCA was negative in all of the previously positive patients, except in two control group patients.

\section{Follow up analyses}

Table 2 shows the outcomes of the 18 CSS patients after a median follow up period of 44 and 55 months, in the treatment and control groups, respectively $(p=N S)$. At the last assessment, three patients in the treatment group were considered to be in treatment free sustained remission, the other patients being in treated remission. Median SNVDI values were 4 (95\% CI 3 to 5 ) and 5 (95\% CI 4 to 6 ) in the treatment and control groups, respectively $(p<0.02$, MannWhitney $U$ test). Permanent disease associated damage was present almost exclusively in the control group and was characterised by fibrosing interstitial lung disease $(n=1)$, moderate renal insufficiency $(\mathrm{n}=2)$, and hemiplegia $(\mathrm{n}=1)$. The modified Rankin scores were reduced to 1.5 (95\% CI 1 to 2 ) and 3 (95\% CI 2 to 4 ) in the treatment and control groups, with a statistically significant difference between the two groups ( $p<0.04$, Mann-Whitney $U$ test). In all of the patients in the treatment group, EMG-ENG examinations documented, to a variable degree, a progressive, although slow, reinnervation process. In the control group, two patients with asymmetrical polyneuropathy displayed a persistent denervation in leg and foot muscles.

There was a clearcut difference in the frequency of relapses, 1/9 for the treatment group and 4/9 for the control group, which occurred in all cases during the first 12 months of treatment. Of the six relapsed patients, four had received cyclophosphamide and the other two had not. Clinical remission was achieved following an increase in the corticosteroid dose.

Neither asthma nor sinusitis was affected by our study protocol.

\section{Side effects}

Table 3 shows the number and type of adverse events recorded during the study period. Only mild side effects such as headache or minor gastrointestinal intolerance were documented following the IVIg infusions or PP sessions, and they did not require modification of the treatment.

Steroid related side effects were the most frequent. We documented a tendency, even though not statistically significant, toward lower incidence of osteoporosis in the treatment group compared with the control group $(\mathrm{p}<0.057$, Fisher's exact test). In this regard, only two patients for each group had osteoporosis at the beginning of the treatment. At the end of the follow up period, the cumulative steroid doses were 11.7 and $16.1 \mathrm{~g}$ for the treatment and control groups,

Table 3 Adverse effects during the whole study period in 18 patients with CSS treated with a "standard" prednisone/cyclophosphamide treatment with (treatment group) or without (control group) IVIg synchronised with PP

\begin{tabular}{lll}
\hline & $\begin{array}{l}\text { Treatment } \\
\text { group } \\
(\mathbf{n}=9)\end{array}$ & $\begin{array}{l}\text { Control } \\
\text { group } \\
(\mathbf{n}=9)\end{array}$ \\
\hline Steroid related & 3 & $8^{*}$ \\
$\quad$ Osteoporosis & 2 & 3 \\
Diabetes & 2 & 4 \\
Arterial hypertension & 1 & 2 \\
Myopathy & 1 & 1 \\
Cushingoid habitus & & \\
Cyclophosphamide related & & 2 \\
Hypogammaglobulinaemia & 0 & 1 \\
Permanent lymphopenia & 1 & 2 \\
Bacterial pneumonia & 1 & \\
\hline *p $<0.057$, Fisher's exact test. & &
\end{tabular}


respectively $(\mathrm{p}<0.005$, Mann-Whitney $U$ test $)$. There was a statistically significant difference in the daily steroid dose between the two groups (mean 5 and $10.35 \mathrm{mg} /$ day of prednisone equivalent in the treatment and control groups respectively; $<<0.002$, Mann-Whitney $U$ test). For cyclophosphamide, the cumulative doses were 21.9 and $23.4 \mathrm{~g}$ for the treatment and control groups, respectively. Among the cyclophosphamide related side effects, only one woman in each group had menstrual irregularities, lasting less than 6 months. None of patients treated with cyclophosphamide developed unexplained microhaematuria during long term follow up.

\section{DISCUSSION}

We treated nine patients with CSS with IVIg and PP associated with oral prednisone. Cyclophosphamide was reserved for patients with severe disease. This combined therapy achieved a remission that was maintained at long term follow up. Compared with the "standard" treatment based on corticosteroids and cyclophosphamide, there was a statistically significant difference in the clinical recovery, the specific laboratory markers, and the overall disease severity, with a lower incidence of adverse effects.

In our series of 18 patients with CSS, the vasculitis scores indicated a mean for active and severe vasculitis, respectively. After initiation of the immunoglobulin infusions, we documented a rapid and sustained recovery. The clinical and biochemical improvement occurring during the first two infusions persisted at long term follow up (a mean of 3 years). We thus documented the resolution of the main disease manifestations: systemic symptoms, alveolitis, myocarditis, renal impairment, cutaneous vasculitis, polyserositis, and arthritis. For the peripheral nervous system, our study demonstrated that the functional recovery was significantly better in patients treated with IVIg than in the control group, even at long term evaluation. At the last assessment, the modified Rankin score medians were significantly different between the two groups. These data are at variance with previous reports. Vasculitis neuropathy causes severe disabling problems from which recovery is usually long and partial, if at all. A delay in the diagnosis or in the start of the treatment could increase the burden of the vasculitic damage in the nerve trunks. As previously reported, the clinical impact of corticosteroids on the neurological involvement may be incomplete. ${ }^{8} 29$

During the disease course, relapses occurred less frequently in the treatment group than in the control group. It should be emphasised that the reported incidence is higher, ranging from 23 to $50 \% .{ }^{12}{ }^{30}$ Furthermore, the strongest probability of relapse occurs in the first 2 years of disease. ${ }^{12}$ The long term favourable course obtained in our patients may be a result of a synergistic effect of the drugs when used as combined rather than single agents.

After a median follow up period of 44 months all of the patients in the treatment group maintained clinical remission, thus permitting a significantly better recovery of peripheral nerve system dysfunction with a statistically significant lower corticosteroid dose in comparison with patients receiving the "standard" treatment. This is further confirmed by the higher incidence of steroid dependent adverse effects (in particular osteoporosis) in this group of patients.

Finally, permanent damage was less prevalent in patients treated with IVIg. At the last assessment, the median SNVDI values were significantly lower in the treatment than in the control group. Considering that baseline characteristics of the patients were similar in both groups, it is conceivable that the lower frequency and severity of disease and/or treatment associated sequelae in the treatment group could be ascribed to better control of the (underlying) disease activity by IVIg and to a reduced total exposure to corticosteroids and/or immunosuppressive drugs.

In the literature, few studies have been specifically performed in groups of patients with CSS only. ${ }^{4-6}{ }^{12}$ The "standard" treatment for CSS is based on corticosteroids and cyclophosphamide. Steroids achieve a good clinical response with a significant decrease in main functional parameters; however, they are associated with a high relapse rate and a greater frequency of side effects. Review of the ample series by Guillevin et al failed to demonstrate that cyclophosphamide could modify long term survival rates. ${ }^{30}$ In addition, corticosteroids alone should be considered only in the absence of manifestations that could result in mortality or severe morbidity. ${ }^{31}$

Other studies have documented an important role for IVIg in the treatment of ANCA associated systemic vasculitis and other immune mediated neuropathies. Despite its limitation as therapy because of availability and cost, IVIg has been shown to be effective alone or as add on therapy. In a recent randomised, placebo controlled trial, Jayne et al documented the efficacy and safety of a single course of IVIg in previously treated ANCA associated systemic vasculitis with persistent disease activity. ${ }^{12}$ To our knowledge ,only single case reports have been published on the use of IVIg treatment in CSS. ${ }^{14-16}$ The rationale for the use of IVIg involves the idiotypic-antiidiotypic mechanism between ANCAs and their antigen $(\mathrm{s})^{33}$ and the blockade of specific ANCA receptor(s) implicated in neutrophil activation and cytokine release in vitro. ${ }^{33}$ In addition, $\mathrm{Yu}$ and Lennon postulated that the acceleration of the rate of the IgG catabolism is probably the most relevant mechanism to explain the benefit of action of IVIg in some autoimmune diseases. ${ }^{17}$ In neuropathies, taking into account evidence from various human and experimental studies, IVIg could also act at other levels, such as suppressing pathogenic cytokines, inhibiting complement binding, preventing membranolytic attack complex formation, modulating T lymphocytes and neutralising bacterial and viral superantigens. ${ }^{13}$

Synchronised therapy has previously been proposed for severe immune mediated diseases. ${ }^{18} \mathrm{PP}$ and IVIg could permit the rapid removal and solubilisation, respectively, from the circulation of the immune complexes formed by ANCA and the antigen MPO. ${ }^{12}$ However, in our study we could not document any beneficial effect for the addition of PP, in agreement with others. ${ }^{5} 7$

In conclusion, our major findings were the complete improvement and long term stable remission with lower side effect rates, as further confirmed by review of previous publications. The limitations of our study are the small sample, the lack of randomisation, and the retrospective analyses of the control group, all linked to the rarity of the disease. In particular, there could be bias because of the retrospective evaluation of BVAS in some subjects in the control group. However, the homogenous clinical and serological features in the two populations, the standardised protocol employed to collect the data, and the results of the longitudinal and statistical analyses should have reduced the relevance of this methodological bias. A randomised controlled trial is warranted to confirm the benefit and safety of IVIg in CSS.

\section{Authors' affiliations}

M G Danieli, M Cappelli, G Malcangi, G Danieli, Istituto Clinica Medica Generale, Ematologia ed Immunologia Clinica Università Politecnica delle Marche, Italy

F Logullo, Istituto di Clinica Neurologica, Università Politecnica delle Marche, Italy

A Salvi, Dipartimento di Emergenza, Ospedale Regionale Torrette di Ancona, Italy 


\section{REFERENCES}

1 Churg J, Strauss L. Allergic granulomatosis, allergic angiitis, and periarteritis nodosa. Am J Pathol 1951;27:277-301

2 Churg A. Recent advances in the diagnosis of Churg-Strauss syndrome. Mod Pathol 2001;14:1284-93.

3 Gross WL. Churg-Strauss syndrome: update on recent developments. Curr Op Rheumatol 2002;14:11-14.

4 Guillevin L, Lhote F, Cohen P, Jarrousse B, Lortholary O, Genereau T, et al. Corticosteroids plus pulse cyclophosphamide and plasma exchanges versus corticosteroids plus pulse cyclophosphamide alone in the treatment of polyarteritis nodosa and Churg-Strauss syndrome patients with factors predicting poor prognosis. A prospective, randomized trial in sixty-two patients. Arthritis Rheum 1995;38:1638-45.

5 Guillevin L, Jarrousse B, Lok C, Lhote F, Jais JP, Le Thi Huong Du D, et al. Longterm followup after tretment of polyarteritis nodosa and Churg-Strauss angiitis with comparisons of steroids, plasma exchange and cyclophosphamide to steroids and plasma exchange. A prospective randomized trial of 71 patients. The Cooperative Study Group for Polyarteritis Nodosa. J Rheumatol 1991;18:567-74.

6 Langford CA, Klippel JH, Balow JE, James SP, Sneller MC. Use of cytotoxic agents and cyclosporine in the treatment of autoimmune disease. Part 2: inflammatory bowel disease, systemic vasculitis, and therapeutic toxicity. Ann Intern Med 1998; 129:49-58.

7 Guillevin L, Cohen P, Gayraud M, Lhote F, Jarrousse B, Casassus P. ChurgStrauss syndrome. Clinical study and long-term follow-up of 96 patients. Medicine 1999;78:26-37.

8 Hattori N, Mori K, Misu K, Koike H, Ichimura M, Sobue G. Mortality and morbidity in peripheral neuropathy associated Churg-Strauss syndrome and microscopic polyangiitis. J Rheumatol 2002;29:1408-14.

9 Jayne DR, Davies MJ, Fox CJ, Black CM, Lockwood CM. Treatment of systemic vasculitis with pooled intravenous immunoglobulin. Lancet 1991;337:1137-9.

10 Richter C, Schnabel A, Csernok E, De Groot K, Reinhold-Keller E, Gross WL. Treatment of anti-neutrophil cytoplasmic antibody (ANCA)-associated systemic vasculitis with high-dose intravenous immunoglobulin. Clin Exp Immunol 1995;10:2-7.

11 Jayne DR, Lockwood CM. Intravenous immunoglobulin as sole therapy for systemic vasculitis. BrJ Rheumatol 1996;35:1150-3.

12 Jayne DR, Chapel H, Adu D, Misbah S, O'Donoghue D, Scott D, et al. Intravenous immunoglobulin for ANCA-associated systemic vasculitis with persistent disease activity. Q J Med 2000;93:433-9.

13 Hahn AF. Intravenous immunoglobulin treatment in peripheral nerve disorders, indications, mechanisms of action and side-effects. Curr Opin Neurol 2000;13:575-82.

14 Hamilos DL, Christensen J. Treatment of Churg- Strauss syndrome with highdose intravenous immunoglobulin. J Allergy Clin Immunol 1991;88:823-4.

15 Armentia A, Fernandez A, Sanchez P, de la Fuente R, Sanchis E, Mendez J, et al. Asthma and vasculitis. Response to intravenous immunoglobulins. Allergol Immunopathol (Madr) 1993;21:47-52.

16 Levy Y, George J, Fabbrizzi F, Rotman P, Paz Y, Shoenfeld Y. Marked improvement of Churg-Strauss vasculitis with intravenous gammaglobulins. South Med J 1999;92:412-14.
17 Yu Z, Lennon VA. Mechanism of intravenous immune globulin therapy in antibody-mediated autoimmune diseases. New Engl J Med 1999;340:227-8.

18 Euler HH, Schroeder JO, Harten P, Zeuner RA, Gutschmidt HJ. Treatment-free remission in severe systemic lupus erythematosus following synchronization of plasmapheresis with subsequent pulse cyclophosphamide. Arthritis Rheum 1994;37:1784-94.

19 Masi AT, Hunder GG, Lie JT, Michel BA, Bloch DA, Arend WP, et al. The American College of Rheumatology 1990 criteria for the classification of Churg-Strauss syndrome (allergic granulomatosis and angiitis). Arthritis Rheum 1990;33:1094-100.

20 Jennette JC, Falk RJ, Andrassy K, et al. Nomenclature of systemic vasculitides. Proposal of an international consensus conference. Arthritis Rheum 1994;37:187-92.

21 van Swieten JC, Koudstaal PJ, Visser MC, Schouten HJ, van Gijn J. Interobserver agreement for the assessment of handicap in stroke patients. Stroke 1988; 19:604-7.

22 Kissel JT, Slivka AP, Warmolts JR, Mendell JR. The clinical spectrum of necrotizing angiopathy of the peripheral nervous system. Ann Neurol 1985; 18:251-7.

23 Hagen EC, Andrassy K, Csernok E, Daha MR, Gaskin G, Gross WL, et al. Development and standardization of solid phase assays for the detection of anti-neutrophil cytoplasmic antibodies (ANCA). A report on the second phase of an international cooperative study on the standardization of ANCA assays. $J$ Immunol Methods 1996;196:1-15.

24 Kimura J. Electrodiagnosis in disease of nerve and muscle: principles and practice. Philadelphia: FA Davies, 1989.

25 Luqmani RA, Bacon PA, Moots RJ, Janssen BA, Pall A, Emery P, et al. Birmingham Vasculitis Activity Score (BVAS) in systemic necrotizing vasculitis. Q J Med 1994;87:671-8.

26 Guillevin L, Lhote F, Gayraud M, Cohen P, Jarrousse B, Lortholary O, et al. Prognostic factors in polyarteritis nodosa and Churg-Strauss syndrome. A prospective study in 342 patients. Medicine 1996;75:17-28.

27 Abu-Shakra M, Smythe H, Lewtas J, Badley E, Weber D, Keystone E. Outcome of polyarteritis nodosa and Churg-Strauss syndrome. An analysis of twenty-five patients. Arthritis Rheum 1994:37:1798-803.

28 Hintze JL. NCSS 2000 quick start and self help manual. Utah: Kaysville, 1988.

29 Hattori N, Ichimura M, Nagamatsu M, Li M, Yamamoto K, Kumazawa K, et al. Clinicopathological features of Churg-Strauss syndrome-associated neuropathy. Brain 1999;122:427-39.

30 Gayraud M, Guillevin L, le Toumelin P, Cohen P, Lhote F, Casassus P et al. Long term followup of polyarteritis nodosa, microscopic polyangiitis and Churg Strauss syndrome. Arthritis Rheum 2001;44:666-75

31 Langford CA. Treatment of polyarteritis nodosa, microscopic polyangiitis, and Churg-Strauss syndrome: where do we stand? Arthritis Rheum 2001;44:508-12.

32 Jayne DRW, Esnault VLM, Lockwood CM. ANCA antiidiotype antibodies and the treatment of systemic vasculitis with intravenous immunoglobulin. $J$ Autoimmunity 1993:6:207-19.

33 Brooks CJ, King WJ, Radford DJ, Adu D, McGrath M, Savage CO. IL-1 beta production by human polymorphonuclear leucocytes stimulated by antineutrophil cytoplasm autoantibodies. Clin Exp Immunol 1996;106:273-9. 